\title{
Author Correction: Multidrug efflux pumps: structure, function and regulation
}

Dijun Du, Xuan Wang-Kan, Arthur Neuberger(D, Hendrik W. van Veen, Klaas M. Pos, Laura J. V. Piddock (D) and Ben F. Luisi

Nature Reviews Microbiology (2018) https://doi.org/10.1038/s41579-018-0048-6

Published online 12 July 2018

In the version of this Review originally published, the author contributions of co-author Arthur Neuberger were incorrectly listed. The author contributions should have appeared as 'D.D., X.W.-K., A.N., H.W.v.V., K.M.P., L.J.V.P. and B.F.L. researched data for the article, made substantial contributions to discussions of the content, wrote the article, and reviewed and edited the manuscript before submission'. This has now been corrected in all versions of the Review. The authors apologize to readers for this error.

https://doi.org/10.1038/s41579-018-0060-x I Published online 18 July 2018 